\title{
MTA1 induced angiogenesis, migration and tumor growth is inhibited by Glycyrrhiza glabra
}

\author{
Sachin Raj M.Nagaraj, Sheela M. Lingaraj, Yashaswini Balaraju, Akhilesh \\ Kumar, Bharathi P. Salimath \\ Department of Studies in Biotechnology, University of Mysore, Manasagangotri Mysore-570006, India
}

\begin{abstract}
Angiogenesis is an important host process that interacts with cancer cells to promote growth, invasion and metastasis. Vascular endothelial growth factor (VEGF) and Metastasis Associated protein (MTA1) are known to play a major role in angiogenesis. The recombinant VEGF and MTA1 proteins were used to induce proliferation and cell migration in MDA-MB-231 cells. Here we investigated the antiangiogenic and antitumor activity of G glabra F6 (G1) on VEGF and MTA1 induced angiogenesis. The angio inhibitory activity of G. glabra F6 (G1) was confirmed by its inhibition of angiogenesis in in vivo assays, peritoneal and chorioallantoic membrane assay. Reduction in the levels of the cytokine VEGF and microvessel density count in the peritoneum of mice treated with G. glabra F6 (G1) indicated that the plant extract decreased VEGF production. It also inhibits the neovascularization in CAM induced by VEGF and MTA1. These findings not only suggest a potential role of VEGF or MTA1 in tumour angiogenesis but it is also an effective beginning to explore mechanism of metastasis and cancer therapy strategy targeting MTA1. Our results suggest that the extract from the roots of G. glabra may be a potential supplemental source for cancer therapy.
\end{abstract}

Keywords - Angiogenesis, Inhibition, Vascular endothelia growth factor (VEGF), Metastasis Associated protein (MTA1), Glycyrrhiza glabra

\section{INTRODUCTION}

Angiogenesis, the growth of new vessels from pre-existing vasculature, is a critical step in tumor progression [1]. New blood vessels are required to support the growth of a tumor beyond the size of about $1-$ $2 \mathrm{~mm}^{3}$, to supply oxygen and nutrients to proliferating tumor cells and for metastasis formation [2-3]. Research in angiogenesis inhibition as a therapeutic strategy against cancer started around 1971, when Folkman postulated that tumor growth is dependent on angiogenesis [4]. In the past two decades, inhibitors of angiogenesis have been developed for clinical use [5]. Most notable angiogenesis inhibitors target the vascular endothelial growth factor (VEGF) signaling pathway, such as the monoclonal antibody bevacizumab (Avastin, Genentech/Roche) and two kinase inhibitors sunitinib (SU11248, Sutent, Pfizer) and sorafenib (BAY43-9006, Nexavar, Bayer). In cancer, there is a balance of pro- and anti-angiogenic factors. However when this balance is disturbed, it results in the so-called 'angiogenic switch' [6]. Tumor cells secrete a number of pro-angiogenic factors that stimulate the proliferation and migration of endothelial cells, resulting in the outgrowth of new capillaries into the tumor [7]. Angiogenesis is regulated by many cytokines including proangiogenic factors, such as VEGF, basic fibroblast growth factor (bFGF), placental growth factor (PIGF), transforming growth factor- $\beta$ (TGF- $\beta$ ), platelet-derived growth factor (PDGF), angiopoietin, angiogenin and interleukin (IL-8) [8-10]. While approximately, $60 \%$ of human cancer expresses VEGF, avastin that inhibits the expression of VEGF or its receptor is found to be effective especially when used in combination with chemotherapy. The VEGF gene is regulated by hypoxia and is under the control of transcription factor Hypoxia inducible factor-1 $\alpha$ (HIF-1 $\alpha$ ) [11]. HIF-1 $\alpha$ is over expressed in premalignant lesions in the colon, colorectal cancer and its metastasis and is also considered to be an independent indicator of poor prognosis [12].

Metastasis Associated Protein (MTA1), the founding member of the MTA family of genes, and is upregulated in human tumors. MTA1 and MTA2 are integral subunits of the nucleosome remodeling histone deacetylation (NuRD) complex and are implicated in chromatin-modifying role [13]. Several studies have identified various roles for MTA1 in normal mammary gland development and human breast cancer progression, including cell proliferation and invasiveness [14]. A recent report suggested that MTA1 may possibly be involved in the regulation of gene expression by covalent modification of histone proteins playing a role in histone deacetylation and transcriptional control [15]. MTA1 and HIF-1 $\alpha$ proteins are expressed in malignant metastatic tumor cells and are therefore expected to have important roles in tumor progression and metastasis during the development of cancer. The cross-talk between MTA1 and HIF-1 has been investigated. It 
also has been shown that MTA1 enhances the stability and transcriptional activity of HIF-1 by recruiting HDAC in human breast cancer cells [13]. According to a previous report that HDAC induces angiogenesis, the deacetylation activity of MTA homologues may potentially be important in regulation of angiogenesis or metastasis.

A balance between angiogenic and antiangiogenic factors has given rise to a significant interest in the use of exogenous antiangiogenic agents for the treatment of tumors and it has been demonstrated that antiangiogenic treatment retards tumor growth. Almost $60 \%$ of drugs approved for cancer treatment are of natural origin. Vincristine, etoposide, taxanes and camptothecines are all examples of plant-derived anticancer compounds. Glycyrrhiza glabra (Licorice) is a favourable herb used in food and medicinal remedies for thousands of years. This herb has long been valued as a demulcent (soothing, coating agent), to relieve respiratory ailments (such as allergies, bronchitis, cold, sore throats and tuberculosis), stomach burn including heart burn from reflux or any other cause, gastritis, inflammatory disorders, skin diseases and liver problems. Glycyrrhizin, one of the main active ingredients of G. glabra is believed to contribute to the herb's many healing properties [16]. Licorice roots contain flavonoids and chalcones [16]. Isoliquiritigin (ISL) and licochalon-A members of the flavonoids have been investigated to have antioxidant, antitumor, anti inflamatory and antiangiogenic activities [18-21]. ISL and licocounarne have been shown to induce apoptosis in colon, gastric and prostate cancer cells. However the antitumor mechanisms of these compounds have not been well defined. ISL, isoliquritin, liquritigenin and isoloquitenin-apioside are licoricen-dervied flavonoids that have been implicated to inhibit angiogenesis and tumor growth [22].

We in our previous report have shown that crude extract of G. glabra (water extracts) inhibits the angiogenic activity [16]. In the present paper attempts have been made to further investigate by activity guided purification, the active principle from G. glabra which is responsible for the antiangiogenic activity. Because angiogenesis is a prerequisite for not only the growth of tumor but also for tumor metastasis. We have identified the ethyl acetate and methanol (80:20) extract of G. glabra to posses anti proliferation and antiangiogenic activity. We have shown that MTA1 is co-expressed by tumor cells and G. glabra extract inhibits angiogenic processes. And also, have show the MTA1 is secreted along with VEGF in the ascites obtained from mouse mammary carcinoma and also MTA1, is a proangiogenic protein. Inhibition of MTA1 induced tumor growth and angiogenesis proves to be effective in proangiogenic therapy.

\section{MATERIALS AND METHODS}

Human Umbilical Vein Endothelial cells (HUVECs) were purchased from Cambrex, USA. MDA-MB231 was purchased from National Center for Cell Science (NCCS), Pune, INDIA. The cells were cultured in 25 $\mathrm{cm}^{3}$ tissue culture flask (NUNC, USA) and grown using Endothelial Growth Medium (EGM-2) for endothelial cells and Dulbeccos's Minimum Essential Medium (DMEM) with 10\% Fetal Bovine Serum (FBS), Streptomycin and Penicillin from GIBCO laboratories, Grand Island, NY, USA. Complete medium was prepared according to the manufacturer's protocol. Incubation was carried out in a humidified atmosphere of 5\% $\mathrm{CO}_{2}$ at $37^{\circ} \mathrm{C}$ and upon reaching to confluency; the cells were passaged after trypsinization. Mice (6-8 weeks Swiss Albino strain) were obtained from the animal house, Department of Zoology, University of Mysore, Mysore, India. All the experiments were approved by the Institutional animal care and use committee of the University of Mysore, Mysore.

\subsection{Plant Material}

The medicinal plant Glycyrrhiza glabra (Leguminosael Fabaceae) (roots) was collected from Western Ghats of Karnataka, India. The plant was identified by a Taxonomist and the identification was confirmed by depositing the voucher specimens in the Herbarium of Department of Studies in Botany, University of Mysore, Mysore, India, by comparing with available voucher specimens. Solvents petroleum ether, hexane, benzene, chloroform, ethyl acetate, acetone, methanol and chemical silica gel were of highest analytical grade and obtained from Sisco research laboratory, Mumbai, India.

\subsection{Fractionation and purification of the active compound from Glycyrrhiza glabra}

Dried and powdered roots of G.glabra $(1 \mathrm{~kg})$ was subjected to polarity based soxhlet fractionation using solvents such as petroleum ether, hexane, benzene, chloroform, ethyl acetate, acetone, methanol, and ethanol. All the solvent extracts were subjected to evaporation to retain the residue. The methanolic extract was finally purified by Silica gel column chromatography (Merck 70-230 mesh) and eluted with ethyl acetate: methanol (80:20). The collected fraction was subjected to thin layer chromatography (data not shown) using chloroform: ethyl acetate: methanol and were pooled based on the bands ( 6 bands) that appeared on TLC. After pooling, the obtained fractions were evaporated to dryness and known concentration of each fraction was tested for activity. The compound F6 (G1) showed maximum effect. 


\subsection{In vivo angiogenesis assays}

2.3.1 In vivo growth of Ehrlich ascites tumor (EAT) cells and peritoneal angiogenic assay

EAT cells $\left(5 \times 10^{6}\right)$ were injected intraperitoneally (i.p) into mice (5 groups of mice, 6 in each group) and growth was recorded everyday from the day of transplantation. To verify the effect of plant extract to inhibit tumor growth and angiogenesis mediated by EAT cells in vivo, the F6 (G1) extract (100 $\mu \mathrm{l}$ ) was injected into the peritoneum of the EAT bearing mice everyday from the $6^{\text {th }}$ day of transplantation. The body weight of the mice was monitored from the $1^{\text {st }}$ day till the $12^{\text {th }}$ day. On the $12^{\text {th }}$ day, the animals were sacrificed and the volume of the ascites formed both in untreated and treated mice were recorded. The pelleted cells were counted by trypan blue dye exclusion method using a hemocytometer. The animals were dissected to observe the effect of the extract on peritoneal angiogenesis [16]. All the experiments were approved by the institutional animal care and use committee, University of Mysore, Mysore, India.

\subsubsection{Immunohistological analysis (H\& E staining)}

To determine the effect of F6 (G1) extract to inhibit the microvessel density. EAT bearing mice were treated regularly with the F6 (G1) extract from the $6^{\text {th }}$ day of transplantation. On the $12^{\text {th }}$ day, the animals were sacrificed and the peritoneum from treated or untreated mice was fixed in $10 \%$ formalin. Sections $(5 \mu \mathrm{m})$ were made from paraffin embedded peritoneum using automatic microtome (SLEE Cryostat) and stained with Hematoxylin and Eosin. Microvessel counts were done by Hot-Spot method [23] and the images were photographed using Leitz-DIAPLAN microscope with attached CCD camera.

\subsubsection{Enzyme Linked Immunosorbent Assay (VEGF/MTA1-ELISA)}

We have standardized a sensitive and specific quantification indirect ELISA system for MTA1. This assay was performed as previously described [24] with modification. About $100 \mu \mathrm{l}$ of cytosolic extract of EAT cells were coated to 96 well microplate using coating buffer and incubated at $4^{0} \mathrm{C}$ overnight. To generate a standard curve, purified MTA1 was diluted in coating buffer at concentrations ranging from $230 \mathrm{pg} / \mathrm{ml}$ to 23 $\mu \mathrm{g} / \mathrm{ml}$. The diluted MTA1 protein standards and aliquots of cytosolic extract of EAT (100 $\mu \mathrm{l} /$ well $)$ were coated to the 96-well microtiter ELISA plates (Nunc MaxiSorp ${ }^{\mathrm{TM}}$, Nunc, USA) using a coating buffer (50 mM sodium carbonate buffer, $\mathrm{pH} 9.6$ ) at $4^{\circ} \mathrm{C}$ overnight. Subsequently, blocked for $1 \mathrm{~h}$ with blocking buffer (5\% BSA/PBS). Anti-MTA1 polyclonal antibody (dilution 1:1000), $100 \mu \mathrm{l} /$ well was added and incubated for $2 \mathrm{~h}$ at $37^{\circ} \mathrm{C}$ followed by incubation with $100 \mu \mathrm{l}$ of secondary antibody $(1: 5,000)$ conjugated to alkaline phosphatase. And developed with $100 \mu \mathrm{l}$ of p-nitrophenyl phosphate solution.

\section{Analysis of VEGF level in EAT Mice treated with F6 (G1)}

In brief, $100 \mu \mathrm{l}$ of ascites sample from F6 (G1) extract treated or untreated mice was coated to 96 well microplate using coating buffer and incubated at $4^{\circ} \mathrm{C}$ overnight. Wells were washed and blocked with blocking buffer (5\% skimmed milk powder in PBS) for $2 \mathrm{~h}$ at $37^{\circ} \mathrm{C}$, followed by incubation with anti VEGF 165 antibodies (1:1000). Recombinant anti mouse VEGF 165 was used to set up the standard curve. After incubation for $2 \mathrm{~h}$, the wells were washed before treating with $100 \mu \mathrm{l} /$ well of goat anti-rabbit IgG conjugated to alkaline phosphatase (1:2000). Incubation was continued for another $2 \mathrm{~h}$ at RT and plate was washed prior to addition of $100 \mu \mathrm{l}$ of the substrate p-nitro-phenyl phosphate (pNPP). After incubation for $30 \mathrm{~min}$ at RT, the reaction was terminated by adding $0.1 \mathrm{~N} \mathrm{NaOH}$ and the absorbance at $405 \mathrm{~nm}$ were measured in a Medispec ELISA reader.

\subsubsection{Chorioallantoic membrane assay}

CAM assay was performed as described previously [25]. In brief, the fertilized eggs were incubated at $37^{\circ} \mathrm{C}$ in a humidified and sterile atmosphere for 10 days. A window was made under aseptic conditions on the eggshell to check for proper development of the embryo. The window was made on $5^{\text {th }}$ day, resealed and allowed to develop further. On the $12^{\text {th }}$ day, saline, recombinant VEGF (10 ng/egg), recombinant MTA1 (10 $\mathrm{ng} / \mathrm{egg})$ with or without the extract $(60 \mu \mathrm{l} / \mathrm{egg})$ were air dried on sterile glass cover slips. The window was reopened and the cover slip was inverted over the CAM. The window was closed again, the eggs were returned to the incubator for another 2 days. The windows were opened on the $14^{\text {th }}$ day and inspected for changes in the microvessel density in the area under the coverslip and photographed.

\subsection{In vitro angiogenic assays}

\subsubsection{Tube formation assay}

In order to study if G. glabra F6 (G1) extract inhibits VEGF or MTA1 induced the formation of capillary like tubes in Human Umbilical Vein Endothelial Cells (HUVECs) a tube formation assay was performed as described in earlier reported by us [26]. Briefly, a 96-well plate was coated with $50 \mu \mathrm{L}$ of Matrigel (Becton Dickinson Labware, Bedford, MA), which was allowed to solidify at $37^{\circ} \mathrm{C}$ for $1 \mathrm{~h}$. HUVECs $\left(5 \mathrm{x} 10^{3}\right.$ cells per well) were seeded on the Matrigel and cultured in EGM media containing different concentrations of VEGF or MTA1 protein (10 ng/ml) or treated with F6 (G1) $(60 \mu \mathrm{g} / \mathrm{ml})$ respectively. The cells were incubated at $37^{\circ} \mathrm{C}$ and $5 \% \mathrm{CO}_{2}$, for $16 \mathrm{~h}$. The next day complete tubes from randomly chosen fields were counted and photographed under an Olympus inverted microscope (CKX40; Olympus, New York, NY) connected to a digital camera at $40 \mathrm{X}$ magnification. 


\subsection{2 ${ }^{3}[\mathrm{H}]$ Thymidine uptake assay}

In order to verify for the in vitro effect of G. glabra F6 (G1) extract on proliferation of MDA-MB-231 cells induced by MTA1 this assay was performed as described earlier [27-28]. Briefly MDA-MB-231 (1x 10 cells per well) were seeded in a six-well plate cultured in DMEM media supplemented with $10 \% \mathrm{FBS}, 1 \mathrm{mg} / \mathrm{ml}$ penicillin/streptomycin and grown in $5 \% \mathrm{CO}_{2}$ at $37^{\circ} \mathrm{C}$ for two days. ${ }^{3}[\mathrm{H}]$ thymidine $(1 \mu \mathrm{Ci} / \mathrm{ml}$ of medium $)$ were added prior to addition of VEGF (10 ng/ml) or MTA1 (10 ng/ml) with G. glabra F6 (G1) extract $(60 \mu \mathrm{g} / \mathrm{ml})$ at different time intervals $(0,6,12,24 \& 48 \mathrm{~h})$ respectively. Similarly in other set of experiment, the MDA-MB231 cells were treated with VEGF $(10 \mathrm{ng} / \mathrm{ml})$ or MTA1 $(10 \mathrm{ng} / \mathrm{ml})$ with G. glabra F6 (G1) extract at different concentrations $(0,10,2040 \& 60 \mu \mathrm{g} / \mathrm{ml})$. After $48 \mathrm{~h}$, the cells were trypsinized and processed for liquid scintillation counting.

\subsubsection{Wound healing assay}

In order to verify for the in vitro effect of G. glabra F6 (G1) extract on migration of MDA-MB-231 cells induced by MTA1 the wound healing assay was performed. The assay was performed as described earlier [29]. In brief, MDA-MB-231 (2x $10^{5}$ cells per well) were seeded in a six-well plate in complete medium and incubated overnight at $37^{\circ} \mathrm{C}$ and $5 \% \mathrm{CO}_{2}$. The cells were serum starved overnight and a wound was scratched on the monolayer using a sterile pipette tip. The plates were washed with PBS twice to remove any detached cells. The cells were treated with mitomycin $\mathrm{C}(10 \mathrm{ng} / \mathrm{ml})$ for $2 \mathrm{~h}$ prior to addition of growth factors with SFM or VEGF $(10 \mathrm{ng} / \mathrm{ml})$ or MTA1 $(10 \mathrm{ng} / \mathrm{ml})$ or treated with G. glabra F6 (G1) $(60 \mu \mathrm{g} / \mathrm{ml})$ in basal media. The wound was photographed subsequently at $0 \mathrm{~h}, 12 \mathrm{~h}$ and $24 \mathrm{~h}$ to visualise the closure of the wound area. The distance moved by cells into the wounded area was enumerated manually.

\subsection{G. glabra F6 (G1) extract inhibits VEGF and MTA1-induced VEGF gene expression}

In order to verify the effect of G. glabra F6 (G1) extract on VEGF gene expression in MDA-MB-231 cells induced by MTA1 the transient transfection assay was performed. The assay was performed as described earlier [27, 30]. In brief, MDA-MB-231 $\left(2 \times 10^{5}\right.$ cells per well $)$ were seeded in six-well plates and cultured at $37^{\circ} \mathrm{C}$ with $5 \% \mathrm{CO}_{2}$ to $60-70 \%$ confluency. On the subsequent day, cells were transfected (calcium phosphate transfection kit, Promega, USA) with $2 \mu \mathrm{g}$ of VEGF promoter-luciferase reporter constructs containing the 5' flanking region (-2068 bp) of human VEGF gene promoter coupled to promoter-less luciferase gene in vector backbone pcDNA3 and $2 \mu \mathrm{g}$ of the $\beta$-galactosidase expression vector RSV- $\beta$-gal as an internal control. The transfected cells were incubated $37^{\circ} \mathrm{C}$ with $3 \% \mathrm{CO}_{2}$ prior to addition of either VEGF $(10 \mathrm{ng} / \mathrm{ml})$ or MTA1 (10 $\mathrm{ng} / \mathrm{ml}$ ) or with G. glabra F6 (G1) extract (60 $\mu \mathrm{g} / \mathrm{ml})$. Cells were washed once with PBS and were serum starved for $48 \mathrm{~h}$. Cells were washed once again with PBS and lysed with reporter lysis buffer. Luciferase (Luc) activity of the cell extract was determined using the luciferase assay system as per manufacturers instruction.

$\beta$-galactosidase ( $\beta$-Gal) activity was determined by measuring hydrolysis of O-nitrophenyl $\beta$-Dgalactopyranoside using $50 \mu \mathrm{L}$ of cell extract at $37^{\circ} \mathrm{C}$ for $2 \mathrm{~h}$. Absorbance was measured at $\mathrm{A}_{405}$ and normalized. Luciferase activity was determined using $50 \mu \mathrm{L}$ of cell extract. The reaction was initiated by injection of $100 \mu \mathrm{L}$ of luciferase assay substrate. Relative luciferase activity (defined as VEGF reporter activity) was calculated as RLU (relative light units per $50 \mu \mathrm{L}$ cell extract)/ $\beta$-Gal activity $\left(\mathrm{A}_{405}\right.$ per $50 \mu \mathrm{L}$ cell extract per $2 \mathrm{~h}$ ).

\section{STATISTICAL ANALYSIS}

Unless stated otherwise, all experiments were performed in triplicates. Wherever appropriate, the data were expressed as the mean \pm SD and means were compared using one-way analysis of variance. Statistical significance of differences between control, VEGF and MTA1 treated cells were determined by Duncan's multiple range test (DMRT). For all tests, $P<0.05$ was considered statistically significant. All of the analyses were performed using the SPSS for Windows, version 13.0 (SPSS Inc.).

\section{RESULTS}

\section{In vivo antitumor and antiangiogenic potential of G. glabra fraction 6 (G1) of methanolic extract}

In our previous paper we have shown that from G. glabra crude extract inhibits angiogenesis [16]. The results on further purification fractionation of the crude extract of G. glabra with activity guided purification of biological active molecule revealed the methanolic extract contained antiangiogenic activity. On further fractionation of the methanolic extract using different ratios of ethyl acetate: methanol, the antiangiogenic activity was traced to fraction F6 of the total 6 fractions. The data shown in fig. 1 clearly indicates that fraction F6 (G1) showed in vivo antitumor and antiangiogenic activity along with suppressing of tumor cell growth and proliferation.

\section{Suppression of peritoneal angiogenesis by G. glabra F6 (G1)}

The results shown in (Fig 2A) indicate, when compared to the 100\% growth of ehrlich ascites tumor (EAT) in the peritoneum of mice there was nearly $50 \%$ decrease in the growth of tumor in the mice treated with F6 (G1) (100 $\mu \mathrm{g}$ /day) for tumor growth period. It is also shown in fig. 2B, C that upon treatment of F6 (G1) the 
volume of ascites and total number of cells in the peritoneum of F6 (G1) treated animals significantly decreased when compared to the control animals.

\section{G. glabra F6 (G1) inhibits VEGF production in EAT cells}

We have detected 138ng/ml VEGF and $22 \mathrm{ng} / \mathrm{ml}$ of MTA1 in either ascites or cytosolic extract of EAT respectively. The representative fig. 2D indicates that F6 (G1) decreases the secretion of angiogenesis factor VEGF in order to exert its antiangiogenic activity in vivo.

$\mathrm{H} \& \mathrm{E}$ immunostaining

Fig. 2E is shown the microvessel density of the mouse peritoneum with and without F6 (G1) treatment, it is evident from the results that MVD has been considerably decreased in the peritoneum of F6 (G1) treated mouse as compared to that of EAT bearing control mice.

\section{VEGF and MTA1 induced angiogenesis in CAM is inhibited by G. glabra F6 (G1)}

In non-tumor context chorioallantoic membrane (CAM) of the chick embryo provides a unique model for investigating the process of new blood vessel formation and vessel responses to antiangiogenic agents. Using this model, we examined the in vivo antiangiogenic activity of F6 (G1). Formation of new blood vessels either in presence of VEGF or MTA1 was evident in our results as shown in fig 3A, B respectively. The VEGF of MTA1 induced CAM treated with F6 (G1) showed significant decrease in neo-vascularization (Fig. 3C, D)

\section{G. glabra F6 (G1) inhibits tube formation of HUVECs in vitro}

The HUVECs adhered to the Matrigel surface within 20-24 $\mathrm{h}$ and form branching, anastomoses network of capillary like tubules with multicentric junctions. As shown in fig. 4A, B VEGF (10 ng) or MTA1 (10 ng) induced tube formation. The F6 (G1) fraction effectively inhibited tube formation induced by VEGF and MTA1 as is shown in fig. 4C, D respectively.

\section{G. glabra F6 (G1) inhibits VEGF or MTA1 induced proliferation in MDA-MB-231 in vitro}

In order to verify the in vitro effect of F6 (G1) on either VEGF or MTA1 facilitated proliferation, a proliferation assay was performed using human breast metastatic cancer MDA-MB-231 cells. As is shown in fig. 5A, there was time dependent increase in the proliferation of MDA-MB-231 cells in presence of VEGF or MTA1. However VEGF or MTA1 induced proliferation was highest at $48 \mathrm{hr}$ when compared to other time periods. Inclusion of F6 (G1) $(60 \mu \mathrm{g} / \mathrm{ml})$ in proliferation assay along with VEGF or MTA1, significantly reduced proliferation of tumor cells. Likewise data in Fig. 5B clearly indicates that F6 (G1) inhibits proliferation in a dose dependent manner.

\section{G. glabra F6 (G1) inhibits VEGF or MTA1 induced cell migration in MDA-MB-231 in vitro}

Wound healing or scratch assay is considered to be an assay to verify the migration of tumor cells and its useful to validate antiangiogenic effects of novel molecule. The data shown in Fig.6A clearly indicate that there is wound closure at $24 \mathrm{hr}$ in presence of VEGF or MTA1. However cell migration induced by either VEGF or MTA1 could be effectively inhibited by F6 (G1) $(60 \mu \mathrm{g} / \mathrm{ml})$. Quantitative analysis of wound healing assay (Fig. 6B) showed that in MTA1 treated of MDA-MB-231 showed more number of cells was involved in closing the wound as either compared to that of SFM or VEGF or G. glabra F6 (G1).

\section{G. glabra F6 (G1) inhibits VEGF or MTA1 induced VEGF gene expression in MDA-MB-231}

The effect of $G$. glabra F6 (G1) extract on VEGF or MTA1 induced VEGF gene expression in metastatic breast cancer cell line MDA-MB-231 was studied by using VEGF promoter-luciferase reporter assay. Results showed that, expression of VEGF was substantially increased on treatment of VEGF or MTA1 (10 $\mathrm{ng} / \mathrm{ml}$ ) protein (Fig. 7). Subsequently, combination of G. glabra F6 (G1) extract (60 $\mu \mathrm{g} / \mathrm{ml})$ with VEGF or MTA1 (10 ng/ml) reduced the VEGF gene expression in breast cancer MDA-MB-231 cells.

\section{DISCUSSION}

MTA1 was previously identified as a metastasis-promoting gene over-expressed in both rat and human cancer cell lines. The expression of MTA1 in human metastatic breast cancer cell line MDA-MB-231, was determined to be approximately 4 times higher than in MDA-MB-468, which is a non-metastatic cell line [31].In this paper we are presenting data indicating that MTA1 is an angiogenic protein. Our result indicates that MTA1 is secreted into ascites in mice bearing EAT cells. Tumor growth and metastasis are dependent on the formation of new blood vessels. The most elegant investigation of the correlation between the onset of angiogenesis and tumor growth was carried out by Folkman et.al [32]. Inhibitors of angiogenesis block any of the steps in the angiogenic cascade, including proliferation and attachment of endothelial cells to the extracellular matrix proteins, migration and invasion through the matrix, which is required for the capillary sprouting and morphogenesis in a thin tube meshwork and stabilization. Given that angiogenesis is essential for tumor growth, the antitumor effects of G. glabra F6 (G1) may correlate with its antiangiogenic activity. In vivo experimental studies have demonstrated that tumor growth and peritoneal angiogenesis have been inhibited by G. glabra F6 (G1). Although MTA1 is over expressed in a variety of human metastatic cancer cell lines and cancerous tissues, the role of this protein in particular steps of metastatic process has not yet been clarified [13]. Our investigation also indicates that MTA1 induces migration of MDA-MB-231 cells as effectively as VEGF. 
This activity is inhibited by G. glabra F6 (G1). This result indicates that both MTA1 and VEGF may adopt the same signalling pathways that control the migration of cells in cancer. G. glabra F6 (G1) inhibits the growth of tumor both in vitro and in vivo as is shown in our data on inhibition of proliferation of MDA-MB-231 cells and the growth of EAT cells in vivo. In support of this, Nawa et.al [33] has shown that the concentration of MTA1 is associated with the rate of proliferation of metastatic and non-metastatic cell lines, where cells expressing more MTA1 are also more metastatic. There are several reports in literature indicating that plants contain potential antiangiogenic active molecules. Deepak et.al has shown that a glycoprotein from Urginea indica inhibits angiogenesis which is mediated by NF-kB [34]. Our result on VEGF gene expression studies indicates that MTA1 per se regulates the expression of VEGF. Our data also reveals that in MDA-MB-231 cells there is an autocrine regulation of VEGF gene expression by VEGF. These results suggest that MTA1 acts synergistically with VEGF to regulate angiogenesis during metastasis. Further, inhibition of either MTA1 or VEGF induced expression of VEGF by G. Glabra F6 (G1) indicates that the plant extract also act at transcriptional level in order to reveal its efficacy as antiangiogenic molecule. Gururaj et.al have shown that curcuimin inhibits VEGF gene expression via, NF-kB [35]. Our previous studies on crude extracts from various plants like Glycyrrhiza glabra, Anacardium occidentale L, Terminelia bellirica, Tinospora cordifolia and Dioscoria bulbifera L have shown to inhibit growth of EAT cells in mice [16, 27, 36-38]. Given that angiogenesis is essential for tumor growth, the antitumor effects of G. glabra F6 (G1) may correlate with its antiangiogenic activity. The current results have also shown that there is inhibition of neovascularization by G. glabra F6 (G1) extract induced either by VEGF or MTA1 protein in the CAM, suggesting that G. glabra F6 (G1) can directly inhibit neovascularisation in a non-tumor context. Inhibition of fluid accumulation, tumor growth, and microvessel density by neutralization of VEGF by G. glabra F6 (G1) demonstrates the underlining importance of VEGF and MTA1 in malignant ascites formation. Since there is inhibition of neovascularization by G. glabra F6 (G1), this supports the view that G. glabra F6 (G1) may repress the expression of VEGF-like factors or inhibit the secretion of such factors, thereby inhibiting the accumulation of ascites fluid and formation of new blood vessels. Further evidence for the antiangiogenic potential of G. glabra F6 (G1) comes from the current results on inhibition of the extent of proliferating endothelial cells in the peritoneal lining of tumor-bearing mice. A significant decrease in peritoneal angiogenesis on peritoneal wall confirmed the antiangiogenic activity of $G$. glabra F6 (G1). Research has demonstrated that the density of microvessels was almost doubled in tumors from patients with metastasis. Thus, an antiangiogenic agent could conceivably block the paracrine action of tumor cells and hence suppress the proliferation and survival of tumor cells. Inhibition of VEGF gene expression by $G$. glabra F6 (G1) should also be reflected by the levels of VEGF in the ascites secreted by the EAT cells. The current results on quantification of the cytokine in the ascites of EAT bearing mice have clearly indicated that $G$. glabra F6 (G1) efficiently decreases the level of VEGF in an in vivo model system. A decrease in ascites formation in vivo and in VEGF levels in ascites bears significant importance in terms of a clinical correlation with inhibited ascites formation in human tumors.

In conclusion, our results suggest that the extract from G. glabra F6 (G1) may be a potential supplemental source for cancer treatment; this study showed that the extracts could efficiently reduce the rate of VEGF and MTA1 induced proliferation and wound healing, suggest that combinational therapy can be used as in treating human breast cancer. Understanding the molecular mechanism of G. glabra F6 (G1) contributes to development of new strategies to inhibit tumor migration and metastasis.

\section{ACKNOWLEDGEMENTS}

This work is supported by funding from Department of Biotechnology (DBT) New Delhi, India (No. BT/PR 11026/Med/30/123/2008), DAE-BRNS, Mumbai, India, IOE-University of Mysore, Mysore and Council for Scientific and Industrial Research (CSIR)-SRF, New Delhi, India for the fellowship.

\section{REFERENCE}

[1]. G. Bergers, and L.E. Benjamin, Tumorigenesis and the angiogenic switch, Nature Reviews, Cancer, 3(6), 2003, 401-10.

[2]. J. Folkman, What is the evidence that tumors are angiogenesis dependent?, Journal of the National Cancer Institute, 82(1), 1990, 4-6.

[3]. H.M.W. Verheul, E.E. Voest, and R.O. Schlingemann, Are tumours angiogenesis-dependent?, The Journal of Pathology, 202(1), 2004, 5-13.

[4]. J. Folkman, Tumor angiogenesis: therapeutic implications, The New England Journal of Medicine, 285(21), $1971,1182-6$.

[5]. J. Folkman, Angiogenesis: an organizing principle for drug discovery?, Nature Review, Drug Discovery,6(4), 2007, 273-86.

[6]. P. Carmeliet, Angiogenesis in life, disease and medicine, Nature, 438(7070), 2005, 932-6.

[7]. R.S. Kerbel, Tumor angiogenesis, The New England Journal of Medicine. 358(19), 2008, 2039-49.

[8]. A. Kumar, S.S. D’Souza, S.R.M. Nagaraj, S.L. Gaonkar, B.P. Salimath, and K.M.L. Rai, Antiangiogenic and antiproliferative effects of substituted-1,3,4-oxadiazole derivatives is mediated by down regulation of VEGF and inhibition of translocation of HIF-1alpha in Ehrlich ascites tumor cells, Cancer Chemotherapy and Pharmacology, 64(6), 2009, 1221-33.

[9]. J.M. Isner, and T. Asahara, Angiogenesis and vasculogenesis as therapeutic strategies for postnatal neovascularization, The Journal of Clinical Investigation, 103(9), 1999, 1231-6. 
[10]. G. Gasparini, and A.L. Harris, Clinical importance of the determination of tumor angiogenesis in breast carcinoma: much more than a new prognostic tool, Journal of Clinical Oncology: Official Journal of the American Society of Clinical Oncology. 13(3), $1995,765-82$

[11]. C. Brahimi-Horn, and J. Pouysségur, The role of the hypoxia-inducible factor in tumor metabolism growth and invasion, Bulletin Du Cancer, 93(8), 2006, E73-80.

[12]. E. Sivridis, A. Giatromanolaki, K.C. Gatter, A.L. Harris, and M.I. Koukourakis, Association of hypoxia-inducible factors 1alpha and 2alpha with activated angiogenic pathways and prognosis in patients with endometrial carcinoma, Cancer, 95(5), 2002, 1055-63.

[13]. Y.G. Yoo Kong G, and Lee MO, Metastasis-associated protein 1 enhances stability of hypoxia-inducible factor-1alpha protein by recruiting histone deacetylase 1, Embo J, 25, 2006, 1231-1241.

[14]. K.-S. Jang, S.S. Paik, H. Chung, Y.-H. Oh, and G. Kong, MTA1 overexpression correlates significantly with tumor grade and angiogenesis in human breast cancers, Cancer Science, 97(5), 2006, 374-9.

[15]. H.E. Moon Cheon H, Chun KH, Lee SK, Kim YS, Jung BK, Park JA, Kim SH, Jeong JW, and Lee MS, Metastasis-associated protein 1 enhances angiogenesis by stabilization of HIF-1alpha, Oncol Rep, 16(4), (2006) 929-935.

[16]. M.L. Sheela, M.K. Ramakrishna, and B.P. Salimath, Angiogenic and proliferative effects of the cytokine VEGF in Ehrlich ascites tumor cells is inhibited by Glycyrrhiza glabra, International Immunopharmacology, 6(3), 2006, 494-8.

[17]. J.S. Kang, Y.D. Yoon, I.J. Cho, M.H. Han, C.W. Lee, and S.-K. Park, Glabridin, an isoflavan from licorice root, inhibits inducible nitric-oxide synthase expression and improves survival of mice in experimental model of septic shock, The Journal of Pharmacology and Experimental Therapeutics. 312(3), 2005, 1187-94.

[18]. H.-M. Kwon, Y.-J. Choi, J.-S. Choi, S.-W. Kang, J.-Y. Bae, I.-J. Kang, J.G Jun, S.S. Lee, S.S. Lim, and Y.H Kang, Blockade of cytokine-induced endothelial cell adhesion molecule expression by licorice isoliquiritigenin through NF-kappaB signal disruption, Experimental Biology and Medicine (Maywood, N.J.). 232(2), 2007, 235-45.

[19]. C.K. Lee, S.H. Son, K.K. Park, J.H.Y. Park, S.S. Lim, and W.Y. Chung, Isoliquiritigenin inhibits tumor growth and protects the kidney and liver against chemotherapy-induced toxicity in a mouse xenograft model of colon carcinoma, Journal of Pharmacological Sciences, 106(3), 2008, 444-51.

[20]. J. Ma, N.Y. Fu, D.B. Pang, W.Y. Wu, and A.L. Xu, Apoptosis induced by isoliquiritigenin in human gastric cancer MGC-803 cells, Planta Medica, 67(8), 2001, 754-7.

[21]. J.I. Jung, S.S. Lim, H.J. Choi, H.J. Cho, H.-K. Shin, E.J. Kim, W.Y Chung, K.K Park, and J.H Park, Isoliquiritigenin induces apoptosis by depolarizing mitochondrial $\mathrm{m}$ embranes in prostate cancer cells, The Journal of Nutritional Biochemistry. 17(10), 2006, 689-96.

[22]. S. Kobayashi, T. Miyamoto, I. Kimura, and M. Kimura, Inhibitory effect of isoliquiritin, a compound in licorice root, on angiogenesis in vivo and tube formation in vitro, Biological \& Pharmaceutical Bulletin, 18(10), 1995, 1382-6.

[23]. J.C. Goddard, C.D. Sutton, D.P. Berry, K.J. O’Byrne, and R.C. Kockelbergh, The use of microvessel density in assessing human urological tumours, BJU International, 87(9), 2001, 866-75.

[24]. S. Shivakumar, B.T. Prabhakar, K. Jayashree, M.G.R. Rajan, and B.P. Salimath, Evaluation of serum vascular endothelial growth factor (VEGF) and microvessel density (MVD) as prognostic indicators in carcinoma breast, Journal of Cancer Research and Clinical Oncology, 135(4), 2009, 627-36.

[25]. K.-Z. Olfa, L. José, D. Salma, B. Amine, S.A. Najet, A. Nicolas, et al., Lebestatin, a disintegrin from Macrovipera venom, inhibits integrin-mediated cell adhesion, migration and angiogenesis, Laboratory Investigation; a Journal of Technical Methods and Pathology, 85(12), 2005, 1507-16.

[26]. S. Ramachandra, S.S. D’Souza, A.E. Gururaj, M.S. Shaila, and B.P. Salimath, Paracrine action of sFLT-1 secreted by stablytransfected Ehrlich ascites tumor cells and therapy using sFLT-1 inhibits ascites tumor growth in vivo, The Journal of Gene Medicine, 11(5), 2009, 422-34.

[27]. S.M. Lingaraju, K. Keshavaiah, B.P. Salimath, Inhibition of in vivo angiogenesis by Anacardium occidentale L. involves repression of the cytokine VEGF gene expression, Drug Discoveries \& Therapeutics, 2, 2008, 234-44C.-C.

[28]. H. Zeng, S. Sanyal, and D. Mukhopadhyay, Tyrosine residues 951 and 1059 of vascular endothelial growth factor receptor-2 (KDR) are essential for vascular permeability factor/vascular endothelial growth factor-induced endothelium migration and proliferation, respectively, The Journal of Biological Chemistry, 276(35), 2001, 32714-9.

[29]. Liang, A.Y. Park, and J.-L. Guan, In vitro scratch assay: a convenient and inexpensive method for analysis of cell migration in vitro, Nature Protocols, 2(2), 2007, 329-33.

[30]. J.T. Buijs Henriquez NV, van Overveld PG, van der Horst G, Que I, Schwaninger R, Rentsch C, Ten Dijke P, Cleton-Jansen AM, Driouch K, Lidereau R, Bachelier R, Vukicevic S, Clézardin P, Papapoulos SE, Cecchini MG, Löwik CW, and van der Pluijm G., Bone morphogenetic protein 7 in the development and treatment of bone metastases from breast cancer, Cancer Res. 67(18), 2007, 8742-8751

[31]. G. Kawasaki, S. Yanamoto, I. Yoshitomi, S. Yamada, A. Mizuno, Overexpression of metastasis-associated MTA1 in oral squamous cell carcinomas: correlation with metastasis and invasion, International Journal of Oral and Maxillofacial Surgery, 37(11), 2008, 1039-46.

[32]. J. Folkman, and Y. Shing, Angiogenesis, The Journal of Biological Chemistry, 267(16), 1992, 10931-4.

[33]. A. Nawa, K. Nishimori, P. Lin, Y. Maki, K. Moue, H. Sawada, et al., Tumor metastasis-associated human MTA1 gene: its deduced protein sequence, localization, and association with breast cancer cell proliferation using antisense phosphorothioate oligonucleotides, Journal of Cellular Biochemistry, 79(2), 2000, 202-12.

[34]. A.V. Deepak, and B.P. Salimath, Antiangiogenic and proapoptotic activity of a novel glycoprotein from U. indica is mediated by NF-kappaB and Caspase activated DNase in ascites tumor model, Biochimie. 88(3-4), ,297-307.

[35]. A.E. Gururaj, M. Belakavadi, D.A. Venkatesh, D. Marmé, and B.P. Salimath, Molecular mechanisms of anti-angiogenic effect of curcumin, Biochemical and Biophysical Research Communications, 297(4), 2002, 934-42.

[36]. Shivakumar, S, Jayashree, K, and B.P.Salimath, Inhibition of Tumor Growth and Angiogenesis by an Aqueous Extract of Terminalia bellirica, Current Trends in Biotechnology and Pharmacy.4(1), 2010, 535-544.

[37]. G. Thippeswamy, M.L. Sheela, and B.P. Salimath, Octacosanol isolated from Tinospora cordifolia downregulates VEGF gene expression by inhibiting nuclear translocation of $\mathrm{NF}-<\mathrm{kappa}>\mathrm{B}$ and its DNA binding activity, European Journal of Pharmacology, 588(2-3), 2008, 141-150.

[38]. K, Kaveri, B, Yashaswini, L, Sheela M, and B. P. Salimath, Evaluation of Antiangiogenic and Antiproliferative Potential in Ethanolic Extract of Dioscoria bulbifera L, Current Trends in Biotechnology and Pharmacy, 4(4), $2010,930-942$. 
Figures and Legends

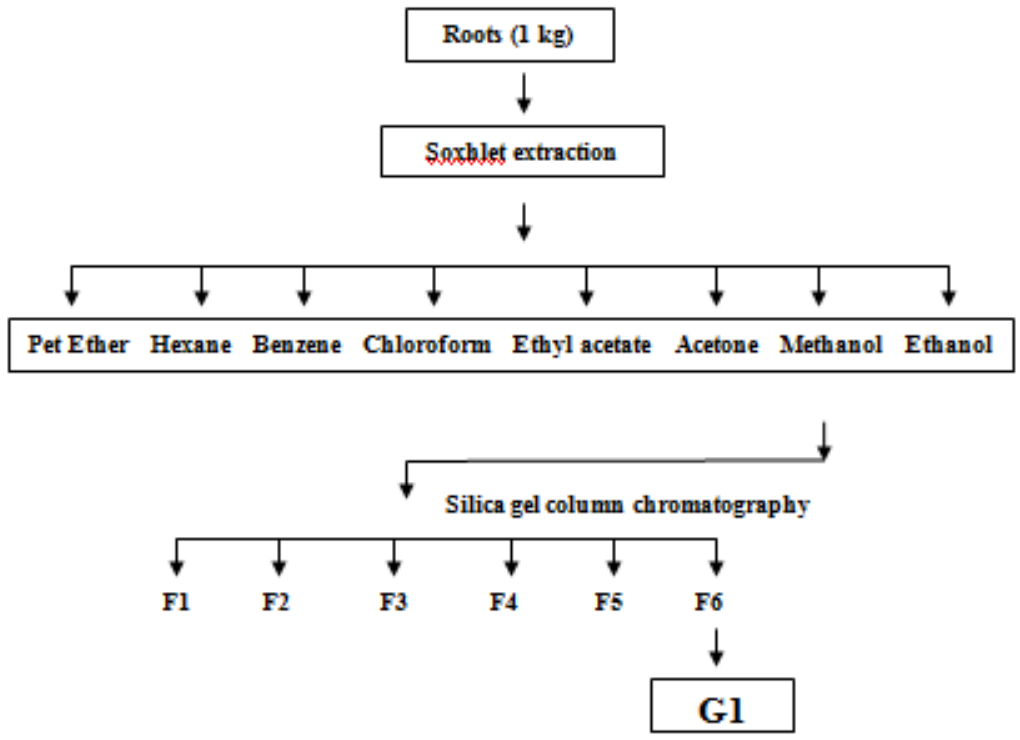

Fig.1The methanolic extract obtained by Soxhlet extraction was further fractionated using a silica gel column chromatography and various ratios of solvents. The anti-angiogenic activity was seen in the fraction eluted with ethyl acetate: methanol (80:20). Further, six fractions were obtained of which F6 (G1) showed substantial antiangiogenic effect.

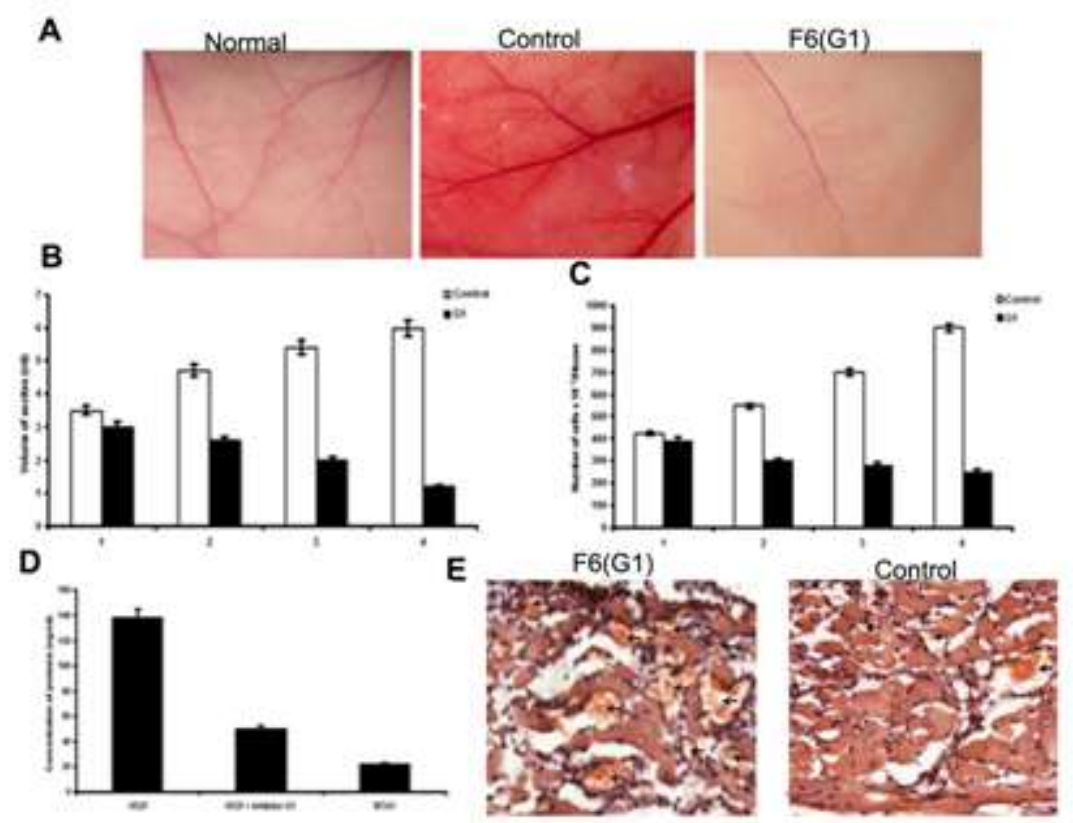

Fig. 2A EAT bearing mice treated with or without F6 (G1) $(100 \mu \mathrm{g} / \mathrm{dose})$ were sacrificed on the $12^{\text {th }}$ day. The animals were dissected and observed for extent of neovascularization. Inhibition of neovascularization is evident in F6 (G1) treated mice. B, C The mice treated with or without F6 (G1) were sacrificed after each dose and the volume of ascites formed was noted. Cells were collected and cell number was counted by trypan blue exclusion method. A drastic decrease in the ascites volume and cell number was observed in a dose dependent manner in the mice treated with F6 (G1). D ELISA was performed with the ascites and cytosolic extract from EAT. VEGF and MTA1 were expressed notably in a higher concentration and it was decreased on treatment with F6 (G1). E 
The peritoneum of control and as well as F6 (G1) treated EAT bearing mice was embedded in paraffin and $5 \mu \mathrm{m}$ sections were taken using microtome. The sections were stained with Hematoxylin and eosin and observed for microvessel density. Arrows indicate the microvessels.
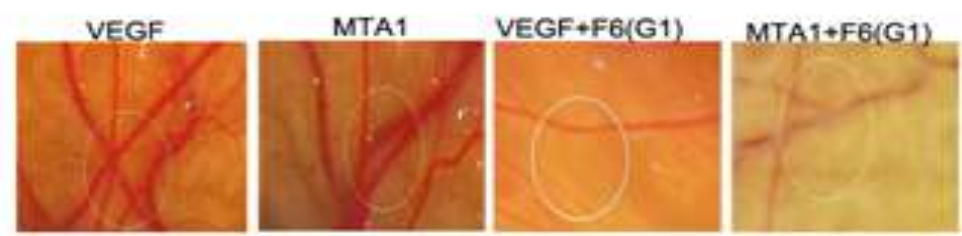

Fig. 3 Induction of Blood Vessel in shell less Chorio Allantoic Membrane (CAM) by VEGF or MTA1 is inhibited by F6 (G1). Chick embryos were cracked out of their shells on to clingfilm hammocks. Egg preparations was covered with sterile petridish and transferred back to incubator. On day 5 a sterile filter disc (2 $\mathrm{mm})$ with PBS or VEGF $(10 \mathrm{ng} / \mathrm{ml})$ or MTA1 $(10 \mathrm{ng} / \mathrm{ml})$ or F6 (G1) $(60 \mu \mathrm{g} / \mathrm{ml})$ were administrated on the CAM.
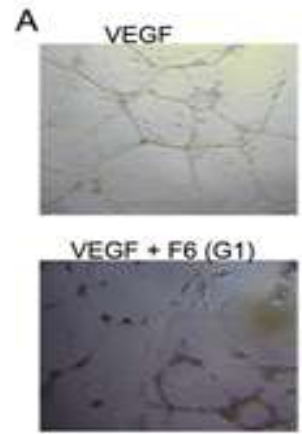
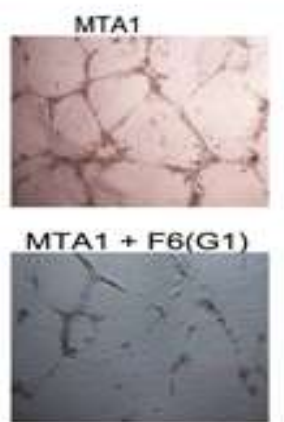

B

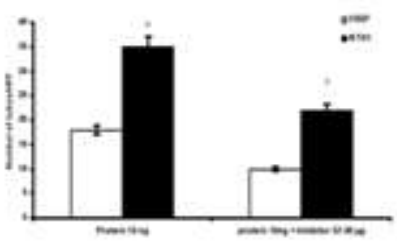

Fig. 4 Induction of endothelial cell tube formation by VEGF or MTA1 by inhibition of F6 (G1).

A Tube Formation Assay in Endothelial cells. Formation of tubes in HUVECs using recombinant MTA1 and VEGF proteins. As described in detail in "materials and methods", HUVECs $\left(5 \times 10^{3}\right.$ cells per well) were seeded onto Matrigel along with MTA1 or VEGF proteins $(10 \mathrm{ng} / \mathrm{ml})$ or F6 (G1) $(60 \mu \mathrm{g} / \mathrm{ml})$ respectively. After incubation for $16 \mathrm{~h}$ at $37^{\circ} \mathrm{C}$, capillary network were photographed and quantified using CCD camera at $40 \mathrm{X}$ magnification. B Quantification of tubes formed in recombinant MTA1 or VEGF or F6 (G1) in HUVECs. NIH image $\mathbf{J}$ was used to determine the total length of tube-like structures in images captured. The data shown is the mean \pm SD of three independent experiments. $\mathrm{a}=$ statistically significant at $P<0.05$ when MTA1 compared with VEGF and $\mathrm{b}=$ statistically significant at $P<0.05$ when MTA1+F6 (G1) compared with VEGF+F6(G1).

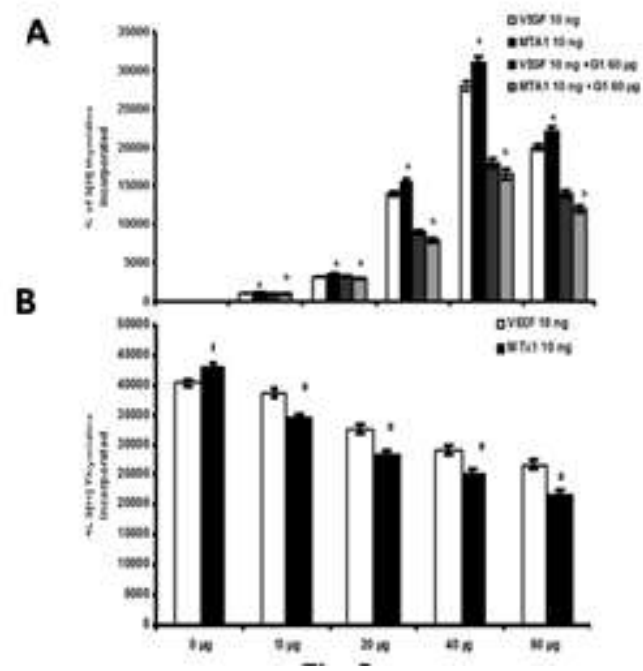


Fig. 5-Effect of F6 (G1) on VEGF or MTA1 induced proliferation of MDA-MB-231 cells. (A, B) As described in detail in materials and methods, MDA-MB-231 (1x $10^{5}$ cells per well) were cultured in vitro in a six-well plate and processed for proliferative activity of recombinant VEGF or MTA1 (10 ng/ml) with inhibitor F6 (G1) in a time dependent manner $(0,6,12,24,48 \& 72 \mathrm{~h})$ respectively. And F6 (G1) in dose-dependent manner ( 0 , $10,2040,60 \mu \mathrm{g} / \mathrm{ml})$ respectively, using ${ }^{3}[\mathrm{H}]$ Thymidine $(1 \mu \mathrm{Ci} / \mathrm{ml}$ of medium $)$. The data shown is the mean \pm SD of three independent experiments. a $=$ statistically significant at $P<0.05$ when MTA1 compared with VEGF and $\mathrm{b}=$ statistically significant at $P<0.05$ when MTA1+F6(G1) compared with VEGF+F6(G1).
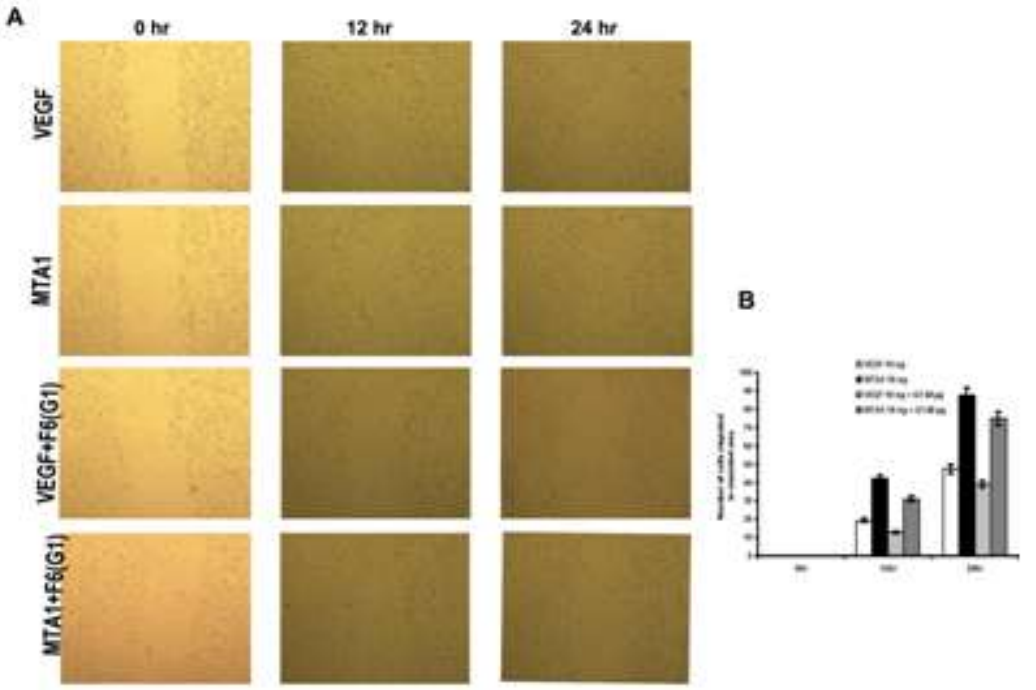

Fig.6 Effect of F6 (G1) on VEGF or MTA1 on closure of wounded area in MDA-MB-231.(A) As described in detail in materials and methods, MAD-MB-231 $\left(2 \times 10^{5}\right.$ cells per well $)$ were seeded in a six-well plate and cultured in DMEM medium. The cells were serum starved overnight and a scratch was made on the cell monolayer. Cell debris was washed and the cells were cultured in medium containing with or without VEGF or MTA1 (10 ng/ml) or F6 (G1) $(60 \mu \mathrm{g} / \mathrm{ml})$. The wound closure was photographed at different time intervals $(0,12$ $\& 24$ h). B. Quantification of the cells involved in wound closure. The cells that moved in the wounded area was counted and expressed as movement of control.

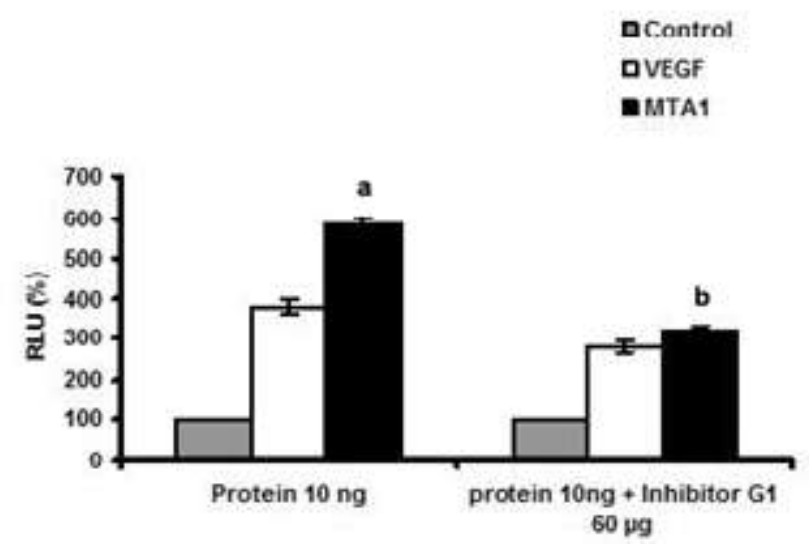

Fig. 7 Effect of F6 (G1) on VEGF or MTA1 induced VEGF gene expression. As described in detail in "materials and methods", MDA-MB-231 $\left(2 \times 10^{5}\right.$ cells per well $)$ was seeded in six-well plates and transiently transfected with $2 \mu \mathrm{g}$ of VEGF promoter-luciferase reporter construct. Cells were treated either with VEGF (10 $\mathrm{ng} / \mathrm{ml})$ or MTA1 $(10 \mathrm{ng} / \mathrm{ml})$ or F6 (G1) $(60 \mu \mathrm{g} / \mathrm{ml})$. Forty-eight hours later, cells were assayed for luciferase activity (luc), and $\beta$-Galactosidase ( $\beta$-Gal) activity was used to normalize as internal control. The data shown is the mean \pm SD of three independent experiments. a = statistically significant at $P<0.05$ when MTA1 compared with VEGF and $\mathrm{b}=$ statistically significant at $P<0.05$ when MTA1+F6(G1) compared with VEGF+F6(G1). 